\title{
Tradições Religiosas e Filosóficas da Índia na Perspectiva de Mircea Eliade
}

\author{
Maria Lucia Abaurre Gnerre ${ }^{1}$ \\ Gustavo Cesar Ojeda Baez ${ }^{2}$
}

\section{RESUMO}

Neste artigo analisamos a perspectiva hermenêutico-filosófica que o historiador das Religiões Mircea Eliade constitui sobre tradição do Yoga e os sistemas religiosos da Índia. Para tanto vamos nos focar na obra Ioga, Imortalidade e Liberdade, publicada pela primeira vez em 1958. Outra obra fundamental que também analisamos recebe a primeira edição em 1962, e intitula-se Patañjalietle yoga ("Patañjali e o yoga"). Neste segundo texto o autor analisa os postulados filosóficos de Patañjali, grande mestre e fundador do sistema do Yoga. Assim, pretendemos evidenciar algumas das principais questões e perspectivas filosóficas sobre as religiões da Índia que são analisadas nas obras de Eliade.

\section{PALAVRAS CHAVE}

Eliade. Índia. Religiões. Yoga.

\footnotetext{
${ }^{1}$ Doutora em História pela Unicamp, docente do Departamento de Ciências das Religiões da Universidade Federal da Paraíba, líder do Grupo Padma (CNPq/UFPB) de pesquisas em religiões e filosofias orientais.

${ }^{2}$ Doutorando em Ciências Sociais pela Universidade Federal da Campina Grande (UFCG) e mestre em Geografia pela Universidade Federal da Paraíba (UFPB).
} 


\section{ABSTRACT}

In this paper we analyze the philosophical and hermeneutic perspective of Mircea Eliade on Yoga tradition and the religious systems in India. In order to do that, we focus on his work Ioga: Imortality and Freedom, first published in 1958. Another work we analyze is Patañjalietle yoga ("Patañjali and Yoga"), first published in 1962. In this last book Mircea Eliade studies the philosophical grounds of Patañjali, master and founder of Yoga System. Thus, we intend to show some questions and philosophical perspectives related to Indian religions of studied by Eliade.

\section{KEYWORDS}

Eliade. India. Religions. Yoga.

\section{Introdução}

Abordaremos neste artigo a perspectiva hermenêutica que o historiador das religiões Mircea Eliade desenvolve sobre a tradição do Yoga na Índia, a partir da análise de seus textos clássicos. Consideramos de fundamental importância este trabalho de revisitar e analisar a produção de Eliade no campo das religiões orientais, tanto pela qualidade inquestionável de seu trabalho, quanto pelo pioneirismo deste, que de certa forma inaugura um processo de compreensão hermenêutica destas tradições no âmbito das academias ocidentais. Embora Eliade tenha sido herdeiro de uma tradição de mais de um século de estudos orientais desenvolvidos em universidades europeias, podemos dizer que suas obras (junto de obras de outros autores que apresentaremos a seguir) inauguram um novo olhar sobre estas tradições, um olhar interessado pela primeira vez em compreendê-las de fato.

Durante muito tempo, estudiosos das mais diversas áreas do saber olharam o oriente como o "outro", como aquilo que não nos pertence. Justamente essa perspectiva pautou boa parte dos estudos acadêmicos do século XIX e início do XX: um misto de exotismo e curiosidade que fascinava os pesquisadores das universidades ocidentais que se 
autodenominavam "orientalistas"3. Esse cenário começou a mudar com alguns estudiosos que, interessados pelas lições do oriente, começam a ler e analisar os textos sagrados para além das diferenças ou para além do mero exotismo. Seguindo esta estrada "surgem" alguns livres-pensadores que vieram a formar Circulo de Eranus, devotados aos estudos sobre o amplo campo das espiritualidades. Nessa vertente temos as produções de C.G. Jung, Heirinch Zimmer, Mircea Eliade e outros pensadores que buscavam estabelecer paisagens mentais comuns nos diálogos entre ocidente e oriente.

Neste grupo, Eliade se destaca por sua proficiência em temas indianos, decorrente justamente do longo período que passa na Índia desenvolvendo sua pesquisa de doutorado (defendida em 1933). Sua tese intitulada Yoga: Essai sur les origines de la mystique indienne ("Ioga: Ensaio sobre a origem do misticismo indiano") foi publicada em francês no ano de 1936. A mesma obra é revista e republicada como Le Yoga. Immortalité et liberté ("Ioga, Imortalidade e Liberdade”), em 1958.

\section{Ioga, Imortalidade e Liberdade}

Podemos dizer que nesta reedição de sua tese de doutoramento Eliade presta conta e homenagens aos mestres e professores que o guiaram nos estudos sobre yoga e sânscrito realizados na Índia. O autor homenageia especificamente seu "ilustre e venerável" mecenas, Maharajah Sir Manindra Chandra Nandie o Prof. Dr. Surendranath Dasguta, diretor da faculdade de sânscrito de Calcutá, onde Eliade estudou no período do final da década de 1920.

Sua obra traça um percurso de apresentação das antigas origens teórico-práticas do Yoga dentro dos diversos caminhos da espiritualidade indiana. Estruturalmente está dividida em oito capítulos, que abordam diversas faces da Yoga. Vamos citar aqui o nome de tais capítulos, pois consideramos esta informação importante para que tenhamos uma visão panorâmica da obra: Capitulo 1 - "As doutrinas do Yoga"; Capítulo

${ }^{3}$ A este respeito, cf. SAID, 1996. 
2 - "Técnicas da autonomia"; Capítulo 3 -“O Yoga e o Bramanismo"; Capítulo 4 - "O triunfo do Yoga"; Capítulo 5 - "Técnicas Yóguicas no budismo"; Capítulo 6- "O Yoga e o Tantrismo"; Capítulo 7- "O Yoga e a Alquimia" e Capítulo 8- "O Yoga e a Índia aborígene".

Como se pode perceber pelos próprios títulos dos capítulos, o autor busca analisar tanto as interações do Yoga com outras disciplinas espirituais como os desenvolvimentos próprios desta tradição. Trata-se, sobretudo, de um imenso esforço intelectual e reflexivo sobre uma bibliografia que foi deslocada - principalmente dos campos da história, da filosofia e dos estudos das línguas (Sânscrito e outras línguas da Índia) - e analisada minuciosamente; uma espécie de tratado sobre o pensamento indiano com vistas a relacionar as formas do yoga e as diversas formas da religiosidade hindu (REDYSON, 2011, p. 47).

Nas páginas iniciais desta obra o autor nos apresenta quatro conceitos fundamentais (e vinculados entre si) que nos introduzem no coração da espiritualidade indiana. São eles os conceitos de Karman, Maya, Nirvana e Yoga. Segundo ELIADE (2010, p. 19), “pode-se escrever uma história coerente de todo o pensamento indiano partindo de cada um destes conceitos", o que levará necessariamente a discutir os outros três. Tais conceitos existem desde a época védica, e podem ser definidos da seguinte forma:

a) Karman: lei da causalidade universal que governa a relação dos homens com os outros homens e o cosmos.

b) Maya: o processo misterioso que gera e sustenta o cosmos tal como o percebemos, e desse modo nos mantém apegados a uma existência ilusória (é uma ilusão cósmica e uma condição de existência suportada pelo homem enquanto está "cego").

c) Nirvana: a realidade absoluta para além da ilusão cósmica e da lei do karman, o Ser em si, o absoluto, que é acessado neste estado de supra-consciência.

d) Yoga: Os meios para atingir o Ser em si, as técnicas adequadas para adquirir a libertação (moksa). A soma desses conceitos constitui o Yoga. 
Esta é a definição inicial de Yoga que Eliade nos fornece: “um conjunto de técnicas que permitem ao homem realizar o si mesmo (partícula do Ser que carrega as suas propriedades chamado de atman), fundir a sua consciência egóica, individual, com a mente universal" (ELIADE, 1996, p. 20). Desde sua origem, o problema central das filosofias da Índia é a busca da verdade, não a verdade para enaltecer o ego do filósofo, mas sim a verdade do conhecimento do Ser como meio para atingir a libertação da ilusão. O fim supremo do sábio na Índia é a conquista da liberdade: "libertar-se equivale impor-se outro plano de existência, apropriar-se de outro modo de ser, transcendendo a condição humana" (ELIADE, 1996, p. 20).

É neste contexto de busca pela liberdade do Ser que Eliade nos apresenta o conceito de Yoga. Afinal, é fundamental compreender a busca pela liberdade como força motriz da própria criação do Yoga. Dai o nome da obra: Yoga, imortalidade e liberdade.

Mas, se analisarmos a origem etimológica da palavra Yoga, podemos pensar a primeira vista que este termo se refere a um conceito oposto ao de liberdade. Afinal, etimologicamente, a palavra Yoga, de origem sânscrita ${ }^{4}$, deriva da raiz yuj ("ligar"), "atrelar", "jungir", "controlar". No período védico, yoga também pode ter significado o ato de jungir os bois, ou seja, cangar, manter juntos, sob jugo, os animais. Mas, como nos lembra o professor Carlos Alberto da Fonseca em sua tradução do Bhagavadgīta $\bar{c}$, "um boi cangado não tem vontade nenhuma..." (FONSECA, 2009, p. 13). Assim, teria havido também uma acepção literal do termo yoga, ainda utilizada nos textos mais antigos da tradição hindu.

\footnotetext{
${ }^{4} \mathrm{O}$ sânscrito é uma língua de origem indo-européia (escreve-se samiskrta) e seu nome designa "bem feito", bem acabado. Trata-se de uma oposição às línguas populares faladas no período védico, consideradas bárbaras pelos povos arianos (GULMINI, 2002, p. 13).

${ }^{5}$ A maioria dos termos em sânscrito serão representados aqui com letras em itálico e com sinais especiais, estabelecidos no início do século XX, que permitem representar os sons do sânscrito com o alfabeto romano modificado. Para compreender o significado de tais sinais, e a pronuncia das palavras em sânscrito, cf. POSSEBON, Fabrício. Curso básico de Sânscrito - prathamampadam. João Pessoa: Ed. UFPB, 2009.
} 
Mas esta mesma, relacionando-o com o significado metafórico que posteriormente adquire, já que o Yoga é uma forma de "cangar" a mente, de controlar pensamentos, e de "jungir" o eu individual, egóico, com o Ser supremo. Assim, é justamente o ato de controle da mente contido no sentido etimológico da palavra que dá origem ao processo de libertação do ser do qual nos fala Eliade em sua famosa obra.

\section{Pressupostos para a compreensão do Yoga de Patañjali na visão de Eliade.}

Os passos para o entendimento do Yoga de Pantajali ${ }^{6}$ expostos na obra Patañjali e o Yoga (2000 [1962]) também partem de uma definição do termo yoga que deriva da raiz yuj (unir, integrar, jungir, por sob o mesmo jugo). Essa definição etimológica, no entanto, vai se desdobrando ao longo do texto para uma compreensão da posição do Yoga dentro dos sistemas filosóficos indianos enquanto um darçana. Esse status de sistema filosófico, adquirido pelo Yoga, ressalta Eliade, somente foi obtido após a compilação de métodos de ascese e meditação milenarmente testados pela cultura hindu, expostos nos famosos Yoga-Sutras de Patañjali.

As controvérsias sobre a antiguidade dos Yoga-Sutras são, decididamente, pouco importantes, pois as técnicas de ascese e de

\footnotetext{
${ }^{6}$ Segundo as narrativas hindus, Patañjali teria uma origem mitológica, sendo uma encarnação de Ananta, o rei milecéfalo das serpentes, que guarda tesouros ocultos na terra. Diz-se que Ananta tomou o nome de Patañjali pois queria ensinar Yoga na terra e caiu (Pat) sobre a palma (añjali) de uma mulher virtuosa. Assim, nesta narrativa mitológica, o sábio Patañjali seria um ser de mil cabeças, que simbolizam a onipresença (FEUERSTEIN, 2005, p. 272). Além desta origem mitológica, não há nada que se possa afirmar sobre Patañjali com grande certeza. Mas supõe-se que tenha sido uma grande autoridade em Yoga, chefe de uma escola de estudos e prática. Seu Yogasūtra apresenta o clímax de um longo período de desenvolvimento de tecnologias yogues. Por isso, de todas as escolas que existiram nos primeiros séculos anteriores e posteriores à era cristã, a escola de Patañjali foi a reconhecida como sistematizadora oficial da tradição do Yoga (GNERRE, 2011, p. 105).
} 
meditação expostas por Patañjali têm certamente uma antiguidade considerável; não são descobertas suas, nem de seu tempo; já haviam sido comprovados experimentalmente muitos séculos antes (ELIADE, 2000, p.17).

Nesse sentido Eliade nos indica que o Yoga torna-se a partir dos Yoga-Sutras um dos seis darçana, ou um dos seis sistemas de filosofia indianos ortodoxos tolerados pelo bramanismo, ao contrário dos sistemas heréticos como, por exemplo, o budismo e o jainismo.

A proposta inicial da segunda obra de Eliade sobre o Yoga é expor uma revisão geral dos conceitos, práticas e pressupostos "filosóficos" presentes nos Sutras de Patañjali. Mas antes de adentrar nas técnicas yóguicas propriamente ditas, o autor percorre um caminho "filosófico", procurando expor os pressupostos soteriológicos presentes nos sistemas do Samkhya ${ }^{7}$ e do Yoga.

Afinal de contas, se constatamos que algo deve ser "religado", isso se deve ao fato de não estar unido, sendo, portanto cindido. Qual é condição humana que determina esta incansável esta busca por se "reconectar" a algo e porque queremos nos livrar da dor universal? Em uma palavra, como podemos sair da condição cósmica da ignorância? O que, enfim, ignoramos?

Segundo Eliade, os textos indianos repetem à exaustão a tese de que a causa da escravidão da alma e, consequentemente, do sofrimento humano, reside na ignorância estabelecida pela solidariedade do homem ao Cosmos. Nossa condição natural, como parte da Prakrti (a matriz fenomênica de toda a existência) nos conduz, inexoravelmente, à ignorância de nossa "real" condição, ou seja: somos uma parte individualizada do Ser universal, do que não morre nem nasce, o próprio Purusa. Essa condição do ser humano de não identificação com a sua real natureza é o que

\footnotetext{
${ }^{7}$ O sāmikhya é uma das mais importantes linhagens filosófica da Índia, que postula uma teoria da causação (ou doutrina do efeito pré-existente). A filosofia do sāmkhhya é reconhecida como uma das seis escolas filosóficas do hinduísmo ortodoxo (darśana). A tradição é um elemento fundamental da filosofia hindu, e a tradição neste caso significa estabelecer uma conexão com a herança védica comum (GNERRE, 2011, p. 81).
} 
gera sofrimento. Estamos, portanto, fazendo parte de um mundo profano, na terminologia de Eliade, participamos de um mundo caído onde tudo se transforma, morre desaparece e, portanto não pertence a esfera do sagrado Ser, perene, estável, imutável, o incriado Purusa.

Por outro lado, essa mesma natureza, o Cosmos, a vida material e psicomental têm uma função ambivalente, quase contraditória, pois é essa mesma vida material que nos ajuda ao "regresso", ao despertar, a salvação da alma, a liberdade absoluta, quando o si individual de dissolve e se identifica completamente com o Si universal (moksha).

Com efeito, quanto mais o homem sofre, ou seja, quanto mais solidário é com o Cosmos, mais nele cresce o desejo de libertação, mais a sede de salvação o atormenta. As ilusões e as formas cósmicas colocam-se assim - e graças ao sofrimento que incessantemente o seu infatigável devir alimenta - ao serviço do homem, cujo objetivo supremo é a libertação, a salvação 'De Brahman ao mais pequeno rebento, a Criação (srshti) é para o bem da alma, até que se atinja o conhecimento supremo' (S.S., III, 47.) O conhecimento supremo, isto é, a libertação não só da ignorância, mas também, e antes de mais, da dor, do sofrimento (ELIADE, 2000, p. 23).

Sendo assim, chega-se a um denominador comum para as escolas de pensamento indianas, heréticas ou não, o pressuposto "motor" da eterna busca do homem. Nesse sentido é apresentado a seguir o caminho do Yoga - o ashtanga yoga (yoga de oito membros) - como um caminho que busca minimizar e até extinguir essa dor, pois sobre o Yoga, "o seu valor reside na capacidade que têm de libertar o homem da dor" (ELIADE, 2000, p. 23).

Sendo assim, neste trecho que trata dos aspectos soteriológicos da filosofia do Yoga temos as condições sem as quais não seria possível buscar o conhecimento supremo. A constatação da dor é a motivação para sair dessa condição humana e cósmica ao mesmo tempo. Deve-se ressaltar nessa medida que nenhuma filosofia resulta do desespero; a dor, e sua constatação ao longo de muitas vidas, são antes e pelo contrário, a condição sine qua non, sem a qual o homem não poderia buscar a libertação. 
A libertação do sofrimento é o objetivo de todas as filosofias e de todas as místicas indianas. Quer essa libertação se alcance diretamente pelo conhecimento seguindo, por exemplo, o ensinamento do Vedanta e do Samkhya - quer por intermédio das técnicas - tal como afirmam, com o Yoga, e a maioria das escolas budistas - a verdade é que nenhuma ciência tem valor se não persegue a 'salvação' do homem. Fora disto nada merece ser conhecido, diz a ÇvetaçvataraUpanishad (I, 12) (ELIADE, 2000, p. 26).

Saindo dos pressupostos soteriológicos, podemos resumir, de forma segura, que a libertação dessa condição da ignorância, logo, se dá unicamente pelo conhecimento do ser Supremo, aquele conhecimento obtido na meditação é que "salva" o homem de sua condição natural. Veremos a seguir que é através de um conhecimento não intelectual, não racionalizado, não sensorial; um "discernimento" (viveka) por assim dizer, que o Yoga promete libertar o ser humano das amarras e ilusões do mundo fenomênico. O despertar é antes de tudo uma tomada de consciência de seu "verdadeiro" espírito, seu próprio centro, o Purusa (Ser) que na sua forma "individualizada" (si) recebe o nome de atman.

Sendo assim todos os passos do Yoga serão destinados a levar a consciência do praticante para esta auto-identificação com o atman. $\mathrm{Na}$ meditação e no distinto samadhi o Si "contempla-se a si próprio" e o objeto da meditação, o ato de meditar e o mediante juntam-se, ligam-se em um só, o almejado estado de Yoga. Nesse sentido, o conhecimento, necessário para cruzar todos os passos do Yoga, se transformará em meditação, e a metafísica indiana se converterá em soteriologia pura.

Para o Samkhya e o Yoga, o problema é claro. Uma vez que o sofrimento tem por fonte a ignorância do 'espírito' (atman) - isto é, o facto de se confundir o 'espírito' com os estados psico-mentais - a libertação só será possível suprimindo tal confusão (ELIADE, 2000, p. 46).

Aqui novamente a noção de discernimento é um ponto crucial para o despertar dentro do Yoga. Chegamos neste ponto a uma diferença fundamental, "divisora de águas", entre Samkhya e Yoga. Embora o objetivo de libertação seja o mesmo, (o despertar que revela a essência do 
Ser) no sistema Samkhya temos que essa tomada de consciência, esse despertar, se dá unicamente pelo conhecimento metafísico. Já no Yoga de Patañjali, por considerar-se essa tarefa um tanto quanto trabalhosa, tem-se a necessidade de realizar um esforço prático através da ascese e das técnicas de meditação.

Sempre é bom lembrar que os sistemas filosóficos Yoga e Samkhya "são de tão forma semelhantes que a maior parte das asserções de um são válidas também para o outro" (ELIADE, 2000, p.18). Vale a pena enfatizar neste ponto que as diferenças decisivas entre os dois sistemas apresentados por Eliade:

As diferenças essenciais entre ambos são poucas: 1. Enquanto Samkhya é ateu, o Yoga é teísta, já que postula a existência de um Deus supremo (Içvara); 2. Enquanto, segundo o Samkhya, a única via de salvação é a do conhecimento metafísico, o Yoga concede às técnicas de meditação uma importância considerável. Em suma, o esforço propriamente dito de Patañjali incide em particular sobre o material filosófico - originário do Samkhya - no que respeita as formulas técnicas da concentração, meditação e do êxtase. [...] Graças a Patañjali, o sistema Yoga, da tradição "mistica" que era, converteu-se num 'sistema de filosofia' (ELIADE, 2000, p. 18).

Ainda sobre as semelhanças entre esses sistemas é importante deixar claro que para o Samkhya como para o Yoga a libertação vem por uma tomada de consciência, não uma consciência ordinária, a consciência do Si, um conhecimento extraracional, obtido somente pela meditação, que conduz à moksa - a libertação final.

Para o Yoga, a diferença sutil se dá na consideração de que o conhecimento não faz senão preparar o terreno para a aquisição da liberdade (ELIADE, 2000, p. 55). Nos dois casos não tratamos de uma experiência intelectual ou dos sentidos. É a supressão da consciência, ou dos estados de consciência normal que levam a dhyana (meditação) e ao samadhi. Esse estado da mente não é facilmente realizável. Ele é obtido, segundo Patañjali, com esforço, com ação correta, com restrições da personalidade humana; a supressão da consciência ordinária implica, portanto, em um conjunto de práticas (abhyasa), numa 
ascese (tapas), isto é, numa técnica fisiológica de supressão do ego. O postulado central éYoga cittavrttinirodha (Y. S., I, 2.); uma tradução aceita seria Yoga é a supressão dos estados de consciência, ou dos fluxos de mente.

Este é o objetivo de todos os passos do Yoga de Patañjali, suprimir, botar sob jugo a consciência ordinária da mente humana e aproximar essa mesma dos seus estados mais elevados ou sutis, estados finais de uma consciência qualitativamente diferente. Evidentemente essa tarefa não é simples para a maioria dos humanos acostumados com a mente ordinária há muitas e incontáveis vidas. Nesse sentido, faz-se completamente necessário um conjunto de técnicas a assertivas que conduzirão o praticante por um caminho seguro de ações em direção à não ação, a meditação e ao supremo samadhi. Assim, percorre-se um caminho que vai do não ser ao Ser, e daí ao conhecer.

Não se pode adquirir nada sem agir e sem praticar a ascese, com efeito só depois de ter experimentado os primeiros resultados desta técnica se pode ter fé (çraddha) na eficácia do método. [...] Mais ainda: só pelas experiências se alcança a liberdade. Assim os deuses (videha-'desencarnados') - que não tem experiência, porque não tem corpo - gozam de uma condição de existência inferior à condição humana e não podem alcançar a libertação completa. (ELIADE, 2000, p. 58)

\section{Os membros do Ashtanga Yoga de Patañjali}

As técnicas sugeridas por Patañjali têm como foco central a meditação concentrada sobre um único ponto - ekâgrata. No caso do Yoga este objeto pode ser físico ou não, uma verdade metafísica, ou ainda um Deus, Içavara. De fato, o que importa nesse caminho óctuplo é extinguir a atividade ou as flutuações normais do pensar que não nos deixam perceber o atman dentro de nós. Começamos com o pensar, concentração correta da mente, que tem como aliado buddhi - a inteligência discriminatória, para depois seguirmos em direção ao não pensar. 
O primeiro dever do yogui é o de pensar, isto é, o de não se deixar pensar pelos objetos. Por isso a pratica do yoga começa pelo ekagrata que bloqueia o fluxo mental e constitui um bloco psíquico, um continuum firme e unitário (ELIADE, 2000, p. 65).

Para alcançar esse fim temos como aliados da inteligência humana - buddhi, o aspecto mais refinado e próximo do Ser - um conjunto de preceitos (como entrega e devoção a prática), e principalmente as técnicas yoguicas que podem ser associadas à possibilidade de invocação e concentração em Içavara.

Patañjali introduz um 'Deus' ao qual não concede, na verdade, senão um papel bastante modesto. Pois o samadhi - como veremos - pode obter-se mesmo sem essa 'concentração em Içavara'. [...] Patañjali teve, no entanto que introduzir Içavara no Yoga, já que Içavara era por assim dizer um dado experimental: com efeito, alguns yoguis faziam apelo a Içavara, ainda que se tivessem podido libertar pela observância exclusiva da técnica Yoga (ELIADE, 2000, p. 92).

Apresentaremos a seguir uma lista com breves comentários de acordo com o texto de Eliade, dos passos que compõe o Yoga de Patañjali, com vistas a alcançar os referidos estados de meditação e samadhi.

\subsection{Refreamentos e disciplinas, os yamas e nyamas}

4.1.1. Yamas ou refreamentos: não são exclusividades da doutrina yoguica, fazem parte das condições básicas ou cuidados para com os próximos. Eles não proporcionam um estado yoguico, mas um estado "purificado" do ser humano. O que se espera com isso é obter equanimidade com a vida social. Essa pureza é indispensável às etapas ulteriores do yoga.

- Ahimsa: não violência ou na matar

- Satya: veracidade ou não mentir 
- Asteya: não roubar

- Brahmacariya: abstinência sexual, controle da energia sexual

- Aparigraha: não ser avaro

\subsubsection{Nyamas: os cuidados consigo}

- Çauca: Pureza. Na codificação tradicional, este item é listado como um Yama; essa palavra significa pureza, limpeza do corpo físico, mental e das emoções.

- Santosa: Contentamento. Quando se trabalha a sensação real de contentamento, satisfação e aceitação dessa vida, objetiva-se a diminuição dos desejos ou vontades agitadoras da mente.

- Tapas: Austeridade, disciplina, convicção, abnegação. Há muitas interpretações para esta prática. Num sentido geral, quer dizer auto supressão dos desejos.

- Svadhyaya: Estudo das escrituras e de si próprio através da prática. Manter a mente atenta para seu mundo real no presente durante a pratica e na vida cotidiana.

- Içvarapranidhana: Auto entrega ou devoção a Içavara. A concentração da mente na meditação e nas ações diárias e a entrega dos resultados a Içavara pode agraciar o praticante com o $s a$ madhi.

\subsection{As posturas yoguicas: âsanas ou postura firme e agradável}

O termo asana vem sendo traduzido simplesmente como postura. Como asana estável, o esforço de manter o corpo na mesma posição (com a coluna ereta), torna-se mínimo, e pode-se almejar o controle mais sutil das outras energias vitais (pranayama) que circulam pelo corpo do yogui. A abolição dos movimentos tem por objetivo abolir também o incessante fluxo de flutuações mentais motivados pelo corpo, assim asana em nível do corpo é um ekagrata, ou seja, busca-se certa neutralidade dos sentidos, o corpo como um todo se concentra numa única posição. "A recusa de se deslocar, de se mover (asana) será continuada por uma série de recusas de todas as espécies" (ELIADE, 2000, p. 73). 


\subsection{Pranayama: a disciplina da respiraçãoou controle da ener- gia vital por meio da respiração e dos bandhas}

A prática do Pranayama envolve uma recusa de respirar da maneira comum. Retenção, controle da respiração e alteração dos estados de consciência foram relações atestadas experimentalmente pelos yoguis desde tempos imemoriais através desta prática. Com esse controle pode-se adentrar nos estados de consciência yoguica, enganar a velhice e na terminologia antiga (Védica ou Upanishadica), superar a morte. Deve ser recebida a orientação direta de um Guru para a prática.

\subsection{Pratyahara: A retração dos sentidos, a última etapa da as- cese psicofisiológica}

As técnicas de asana e pranayama que apresentamos antes imitam os aspectos divinos de imobilidade, estabilidade e autonomia invulnerável concentrada em si mesmo atribuídos a Içavara. Iniciam, portanto, o praticante no processo de autonomia em relação ao Cosmos: o yogui imita o modo de ser Supremo do espirito puro, Içavara. Já em Pratyahara temos o yogui fechando-se numa "blindagem" transcendente da condição humana, nada externo o perturba, e cittavritti (as flutuações da mente) começam a ser suspensas. Daqui por diante, afirma Eliade, o yogui "não será distraído ou perturbado pelos sentidos, pela atividade sensorial, pela memória" (ELIADE, 2000, p. 85).

\subsection{Dharana: concentração ou conjunção}

Eliade trata dos três estágios finais (dharana, dyana e samadhi) como formas conjuntas quase ligadas, em suas palavras:

Lembremos que os três últimos «membros do yoga〉 representam 〈experiências〉 e 〈estados〉 tão intimamente ligados entre si que se lhes atribui o nome: samyama. Realizar samyama de um certo plano significa: realizar ao mesmo tempo a concentração (dharana), a meditação (dhyana) e a stase (samadhi)[...] A passagem da concentração à meditação não requer qualquer técnica nova. 
Do mesmo modo, não é necessário nenhum exercício yoguico suplementar para realizar samadhi. (ELIADE, 2000, p. 95).

\subsection{Dhyana: a meditação yoguica.}

Neste estado, a corrente de pensamento unificado do praticante tende ao não pensar. É praticamente indescritível, impessoal e intransferível para o plano das palavras.

\subsection{Samadhi: estado extático em que se torna possível a auto- revelação do Si (purusa), um "ato fora da experiência"}

Trata-se da libertação final, onde todo vrtti é eliminado e o si se unifica com o $\mathrm{Si}$. A consciência humana é suprimida, isto é, deixa de funcionar, pois seus elementos constitutivos são unificados e reabsorvidos na substancia primordial. O yogui alcança a libertação final tal como um morto em vida, um jivanmukta ou o liberto em vida. A descoberta de si mesmo, autorreflexão do purusa conduz a uma ruptura ontológica do homem, onde são abolidas as modalidades do real. O Ser supremo (purusa) coincide sobre o si humano. A autorevelação pode ser equivalente a uma tomada de posse do Ser em toda sua plenitude (ELIADE, 2000, p. 120).

\section{Considerações finais}

Após apresentar todos os passos do Yoga descritos no texto de Patañjali, Eliade (2000) retoma sua abordagem hermenêutica, apresentado o sistema do Yoga como chave explicativa para a compreensão do modus operandi de toda a espiritualidade hindu:

O Yoga está sempre presente na espiritualidade indiana, tanto na tradição oral como na literatura sânscrita e vernacular. O que equivale a dizer que o Yoga constitui uma dimensão específica da espiritualidade indiana. A tal ponto que, quando o cristianismo se adaptou as realidades indianas, fez seus alguns dos métodos do Yoga de meditação e oração (ELIADE, 2000, p. 129). 
Essa afirmação de Eliade, do Yoga como uma forma de espiritualidade característica da Índia que se insere em diversos sistemas religiosos a tal ponto que foi captada pelos missionários cristãos como forma de "dialogar" com os hindus, é muito relevante. Sem dúvida, temos mostras disso nos exercícios espirituais que são desenvolvidos por Jesuítas, sobretudo após seu contato com a Índia.

Sobre esta importante inegável inserção do Yoga em toda a espiritualidade hindu, prossegue Eliade:

O Yoga constitui uma dimensão específica da espiritualidade indiana, a tal ponto que nos lugares onde a religião e a cultura indiana penetraram se encontra igualmente uma forma mais ou menos pura do Yoga. Na Índia, o Yoga foi integrado e valorizado por todos os movimentos religiosos, tanto hinduístas como 'heréticos'. Os diferentes Yoga sincretistas da Índia moderna constituem ainda uma prova de que a experiência religiosa indiana exige como uma necessidade os métodos yoguicos de 'meditação' e de 'concentração'. De facto, o Yoga acabou por absorver e integrar toda a espécie de técnicas espirituais e místicas, das mais elementares às mais complexas (ELIADE, 2000, p. 201).

É justamente através da análise hermenêutica da tradição do Yoga que o autor a percebe como um conjunto integrado de práticas e conhecimentos filosóficos apropriados "por e para" múltiplas espiritualidades indianas. O movimento é tanto de aproximação das religiões na direção do Yoga quanto do Yoga se inserindo no corpo dos movimentos religiosos hindus. Ou seja, a dimensão específica do Yoga dentro da espiritualidade indiana é a de ser o fio condutor que liga os vários caminhos espirituais como as pérolas a um colar - para utilizarmos uma metáfora tão famosa nesta tradição. Yoga é o sutra (o fio condutor) - e as diversas formas de espiritualidade são as próprias pérolas. 


\section{Referências}

ELIADE, Mircea. Patañjali e o Yoga. Lisboa/Rio de Janeiro: Relógio D'Água Editores, 2000.

ELIADE, Mircea. Yoga: imortalidade e liberdade. São Paulo: Palas Athena, 2004.

FERREIRA, Mário. "A terminologia técnica do Yoga Clássico". ROJO, Marcos (org.). Estudos Sobre Yoga. São Paulo: Phorte, 2006.

FERREIRA, Mário; GNERRE, M. L. A.; POSSEBON, Fabrício. Antologia Védica. $1^{\mathrm{a}}$. ed. João Pessoa: Editora Universitária UFPB, 2011.

FEUERSTEIN, Georg. A Tradição do Yoga. São Paulo: Pensamento, 2005.

GNERRE, M. L. A. Religiões Orientais: Uma introdução. João Pessoa: Editora Universitária UFPB, 2011.

GNERRE, Maria Lucia Abaurre. GHERAṆDA SAṂHTĀ: Corpo e Libertação na Tradição Hatha Yoga. Numem 23, v.14, n.2, Juiz de Fora: PPCIR/UFJF, 2011.

GULMINI, Lilian. O Yoga Sutra de Patañjali: tradução e análise da obra a luz de seus fundamentos contextuais, intertextuais e lingüísticos. Dissertação de Mestrado: Faculdade de Filosofia, Letras e Ciências Humanas/ USP, 2002.

LOUNDO, Dilip. "Ser Sujeito": Considerações sobre a noção de Atmannos Upanishads. Resumos do $1^{\circ}$ Seminário Internacional Consciência, Mente \& Corpo Casa da Ciência, Campus da Praia Vermelha/UFRJ, Rio de Janeiro - 17 a 21 de Agosto 2011.

LOUNDO, Dilip. "O ritual na tradição védica: abertura, pluralidade e teleologia”. GNERRE, Maria Lucia (org.). Cultura oriental: língua, filosofia e crença. $1^{a}$ ed. João Pessoa: Editora da Universidade Federal da Paraíba, 2012, pp. 31-56.

MONIER-WILLIAMS. A Sanskrit-English Dictionary.Oxford, England: Clarendon Press, 1988.

POSSEBON, Fabrício. Curso básico de Sânscrito - prathamampadam. João Pessoa: Editora UFPB, 2009.

REDYSON, Deyve. Introdução ao pensamento de Mircea Eliade. João Pessoa: Editora UFPB, 2011. 
SAID, Edward. Orientalismo - O Oriente como invenção do Ocidente. São Paulo: Companhia das Letras, 1996.

ZIMMER, Heinrich. Filosofias da Índia. São Paulo: Palas Athenas, 2003. 